\title{
POST-BUCKLING DEFORMATION STATES OF SEMI-MONOCOQUE CYLINDRICAL STRUCTURES WITH LARGE CUT-OUTS UNDER OPERATING LOAD CONDITIONS. NUMERICAL ANALYSIS AND EXPERIMENTALTESTS
}

\section{STANY ZAKRYTYCZNYCH DEFORMACJI PÓŁSKORUPOWYCH KONSTRUKCJ WALCOWYCH Z DUŻYMI WYKROJAMI W WARUNKACH OBCIĄŻEŃ EKSPLOATACYJNYCH. ANALIZA NUMERYCZNA I BADANIA EKSPERYMENTALNE*}

\begin{abstract}
The paper is a presentation of experimental model studies on thin-walled cylindrical structures containing large cut-outs subject to torsional deflection. The effect of rigidity of the frame reinforcing a cut-out on form and magnitude of post-buckling deformations occurring in operation conditions is analysed. A methodology based on numerical tools is proposed for determining alternative solutions in the design of structure skeleton leading to improvement of operation stability.
\end{abstract}

Keywords: operating loads, loss of stability, thin-walled structures, aircraft load-bearing structures, torsional deflection, finite element method, nonlinear numerical analyses, operating stability.

\begin{abstract}
W pracy zaprezentowano wyniki modelowych badań eksperymentalnych cienkościennych, skręcanych struktur walcowych zawierających duże wykroje. Przeanalizowano wpływ sztywności ramy wzmacniającej wykrój na postać i wielkość deformacji zakrytycznych, występujących w warunkach eksploatacji. Zaproponowano metodykę określania alternatywnych rozwiąań konstrukcyjnych szkieletu struktury, zapewniające poprawę trwałości eksploatacyjnej, w oparciu o narzędzia numeryczne.
\end{abstract}

Stowa kluczowe: obciażenia eksploatacyjne, utrata stateczności, ustroje cienkościenne, lotnicze struktury nośne, skręcanie, metoda elementów skończonych, nieliniowe analizy numeryczne, trwatość eksploatacyjna.

\section{Introduction}

The dynamic evolution of solutions used by designers of aircraft load-bearing structures, initiated in the 1920 s, resulted in establishment of aircraft operation standards based on assumptions which would be unacceptable for any other type of engineering structures. One of such assumptions is the admissibility of post-buckling deformations of semi-monocoque skin structures provided that the loss of stability is of local and linear-elastic nature $[1,2]$. The rule applies mainly to skins made of isotropic materials, because in case of glass, carbon, and aramid composites which are used in the aircraft industry for a relatively short period of time, destruction processes occurring in the course of their prolonged operation in post-buckling deformation conditions are still the subject of numerous studies [6-8, 10, 13, 19].

Although composites become more and more popular in the aircraft technology, aluminium alloys still remain the materials most universally used by the industry for their well-known mechanical properties and high reliability. Application of these materials for aircraft skins was initially connected with some distrust as designers traditionally strove after elimination of post-buckling deformations in the first place. In such cases, the need to increase skin thickness emerged resulting in inevitable increase of the overall mass of the structure. For some time, the problem had been solved by using corru- gated sheet metal for fuselage skins. This technology was commonly applied only in the beginning of 1930 s, e.g. in designs of such aeroplane manufacturers as Ford and Junkers. With improvement of aircraft performance parameters, such structures became more and more troublesome because of the related aerodynamic problems, as a result of which it became necessary to coma back to smooth skin materials and admit the possibility of occurrence of local post-buckling deformations $[11,14]$.

While in case of skin fragments without geometrical singularities, the above-mentioned phenomenon does not result in any decrease of their operating durability stability, presence of cut-outs of any type becomes a source of problems. Aircraft structures, by virtue of for what they are intended and in what conditions are to be operated, are characterised with existence of a large number of cut-outs with various dimensions. Such discontinuities may occur within segments of skin of a semi-monocoque structure limited by skeleton components (e.g. passenger cabin windows or small inspection openings). They can also represent major discontinuities of the structure with larger dimensions, e.g. doors, cargo loading hatches, or large access openings (Fig. 1), which make segmentation of stringers necessary.

From the point of view of strength properties and operating durability of a structure, presence of cut-outs is a very unfavourable circumstance. They reduce overall rigidity of the structure and force

(*) Tekst artykułu w polskiej wersji językowej dostępny w elektronicznym wydaniu kwartalnika na stronie www.ein.org.pl 

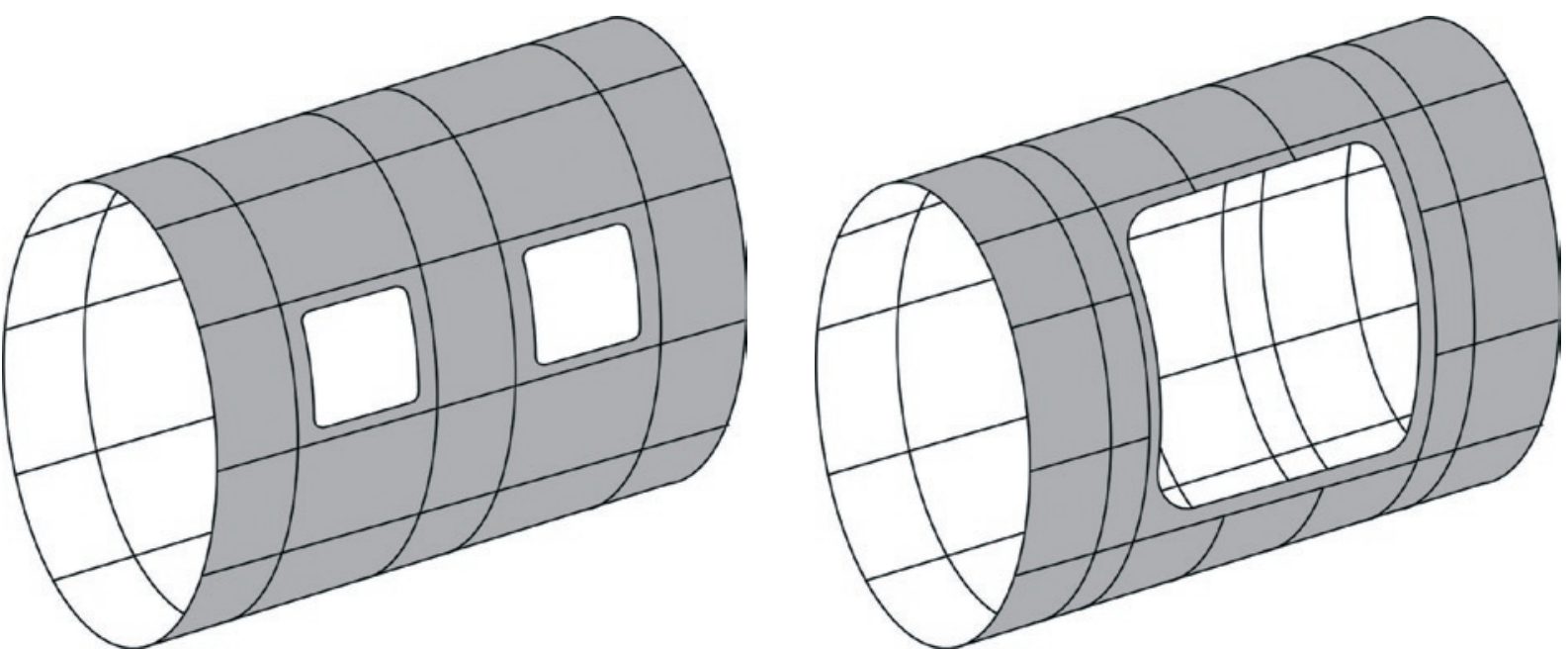

Fig. 1. Examples of cut-outs in aircraft structure skins

the designers to use additional structural elements in the form of sufficiently rigid frames, which in turn contributes to an increase of the aircraft mass. Moreover, cut-outs represent those zones of any structure which are most susceptible to fatigue-induced damage zone capable to end up with a very serious failure or even destruction of the whole object $[1,12,16,18,20]$.

In the course of research on aircraft structures, design teams have worked out a number of design canons securing the safety margin required by applicable norms to be maintained in operating conditions. It should be however emphasised that many of these commonly adopted standards were established at the technology development level when numerical tools still had not been available and each of the new solutions had to be verified in the course of costly experimental tests.

Nowadays, it is possible to carry out virtual experiments with the use of sophisticated engineering tools, including software packages based on the finite element method. Moreover, recent progress in the materials engineering has broadened significantly the range of options available when relatively inexpensive experiments with the use of model materials are planned. It seems to be therefore appropriate to undertake attempts aimed at finding alternative design solutions focused on securing as high reliability of the structure as possible, with its mass reduced to a minimum at the same time [12].

This paper presents a number of results obtained from experiments and numerical analyses concerning a representative fragment of semi-monocoque aircraft load-bearing structure weakened by presence of a cutout.

\section{Purpose and scope of the study}

The subject of the study was a typical fragment of aircraft load-bearing structure weakened by presence of a cut-out (Fig. 2), corresponding to e.g. a helicopter tail boom with an inspection opening providing access to the tail rotor drive shaft or a separated aeroplane fuselage fragment with a window.

In similar cases, the most commonly adopted design canon provides for situating the cut-out between neighbouring elements of the skeleton, with cut-off wedges situated as close as possible to joints between the skeleton and the skin. In practice, implementation of this imperative runs up against a number of limitations. The most fundamental of them is the necessity to reinforce the cut-out with an appropriate frame the role of which consists not only in providing sufficient rigid- ity to the skinless segment of the structure but also allowing to mount the glass pane in an aeroplane window or the cover to an inspection opening.

If, moreover, a design provides for cut-out edge with too small round-off radii, there is a high risk of deterioration of the overall operating durability caused by nucleation of fatigue cracks.

Another rule adopted commonly in the design processes is aspiring to minimise post-buckling deformations by means of reinforcing the skeleton through introducing many additional components to its structure. The final result is usually the increased mass of the structure accompanied by overall overdimensioning in many cases.

The purpose of the study was to determine the effect of rigidity of the frame reinforcing a cut-out on the nature of post-buckling deformations of the skin and identify design solutions allowing to increase critical load levels and thus also the service life of the structure, with as little skeleton components as possible.

The study's point of departure was an experiment with a model tested on a dedicated research set-up. Skin deformations were observed by means of an optical scanner. High optical sensitivity of the material from which the model was made allowed to carry out qualitative assessments of stress distribution patterns by means of optical

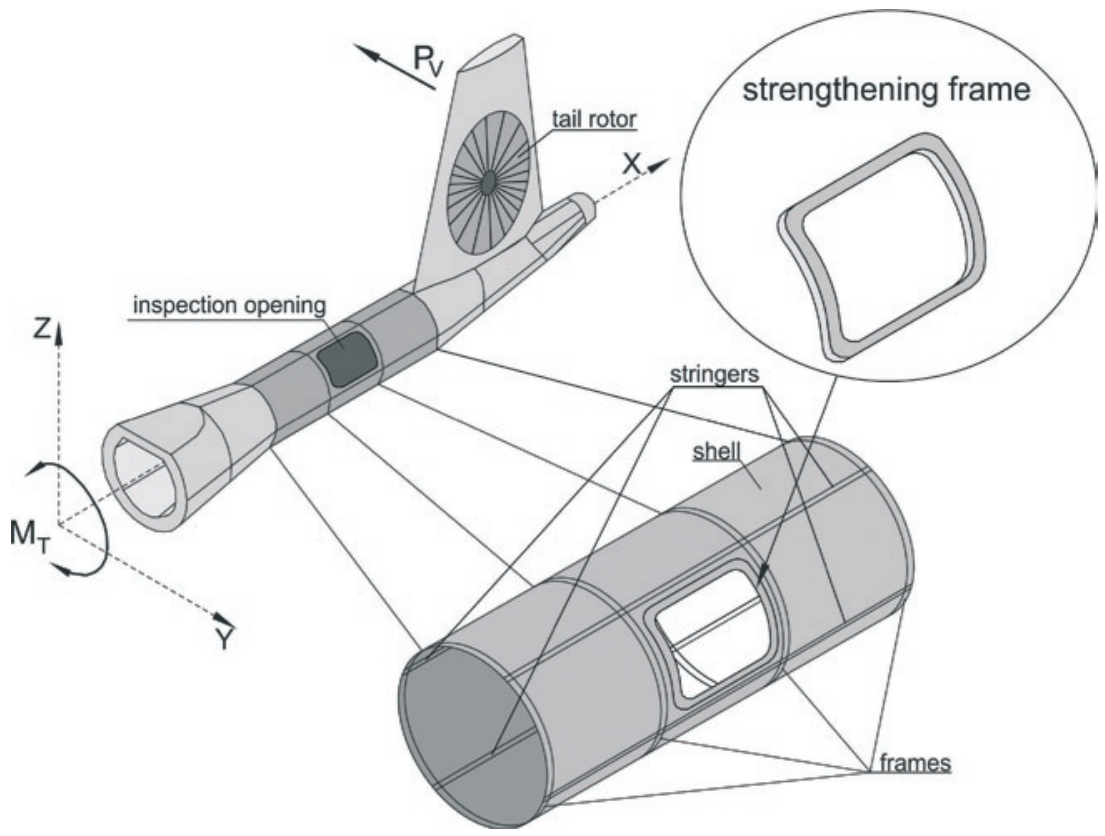

Fig. 2. An example of location of the examined object in the aircraft structure 
polarimetry methods. The experimental data were used as a base on which results obtained from nonlinear analyses carried out by means of the finite elements method were verified. Development of an appropriate numerical model allowed to identify structural design solutions meeting assumed mass- and stiffness-related criteria.

\section{The experiment}

The subject of the model experiment was a thin-walled cylindrical structure reinforced by means of four stringers and four frames (Fig. 3). The outermost closing frames were solid elements, while frames in the area of the cut-out had a fragmentary form.

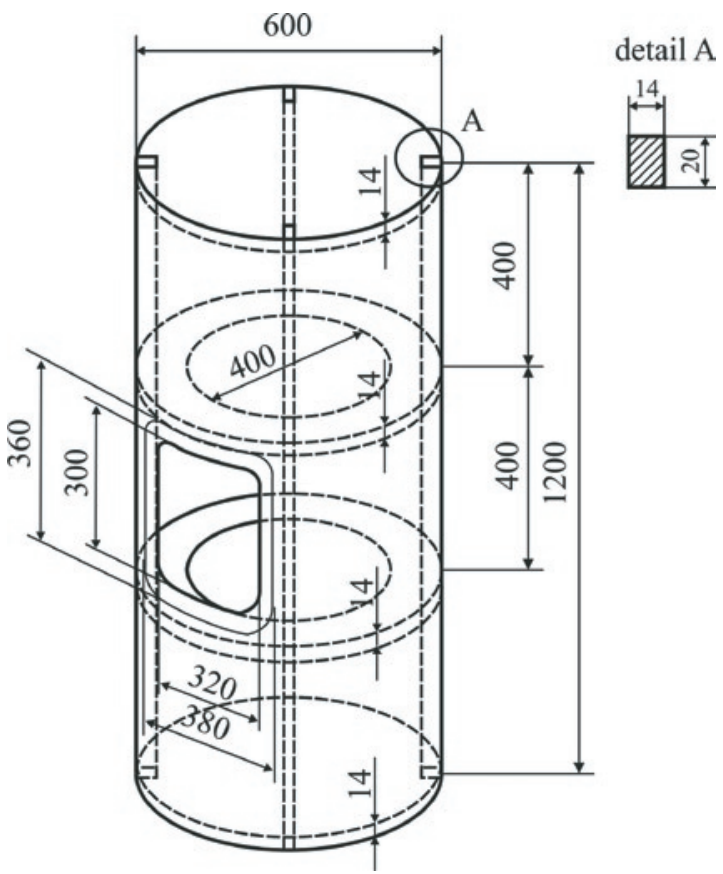

Fig. 3. Schematic view of the structure

Models of all variants of the structure were made out of polycarbonate marketed under trade name of Makrolon for which the tensile strength test was carried out and the following material constants determined: the Young's modulus $E=3000 \mathrm{MPa}$ and the Poisson ratio $v=0.36$.

The characteristic of the material corresponding to one-dimensional tensile stress was also determined (Fig. 4). Clearly distinguishable elastic and inelastic deformation zones suggest the possibility to approximate the actual material characteristic by the ideal elasticplastic model. However, due to the fact that only a local elastic loss of

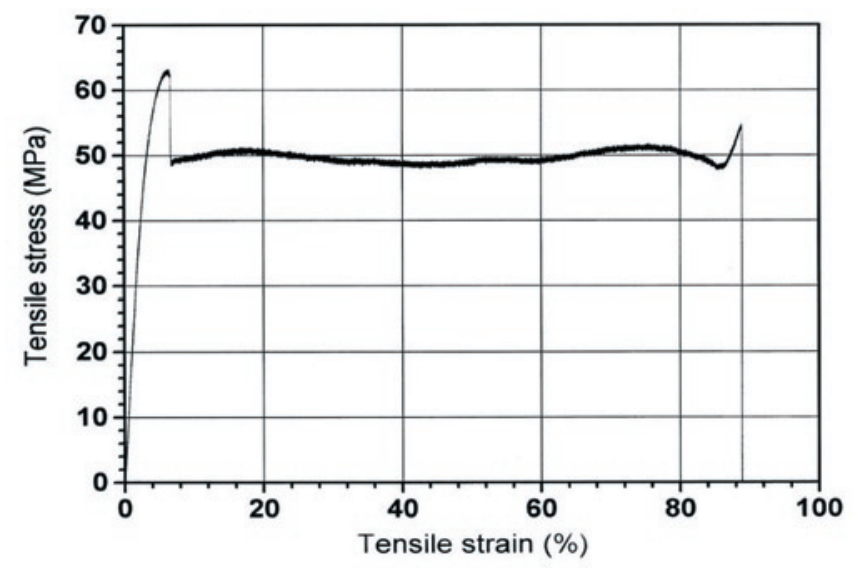

Fig. 4. The tensile stress plot for the polycarbonate specimen

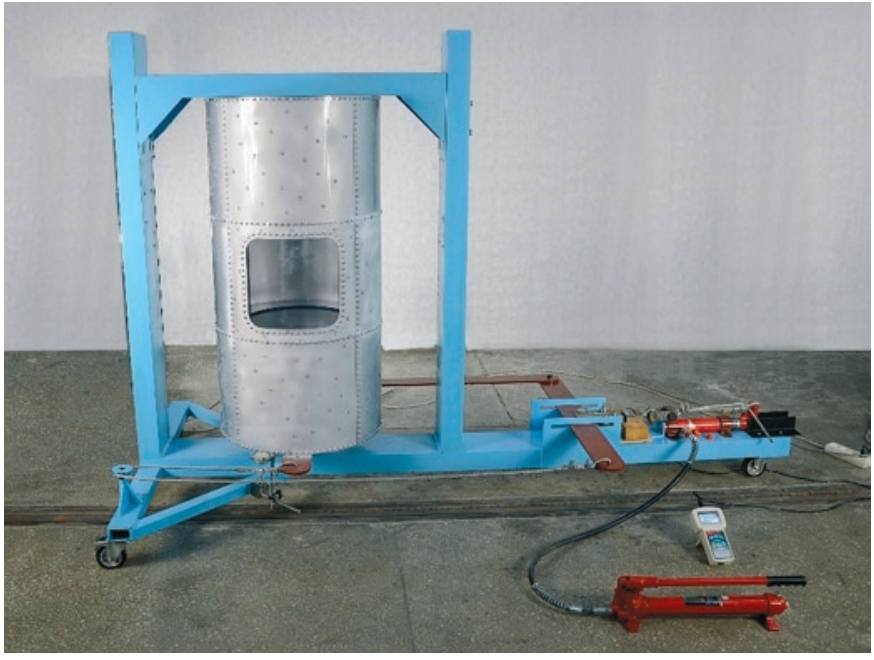

Fig. 5. The research set-up with the model subject to the experiment
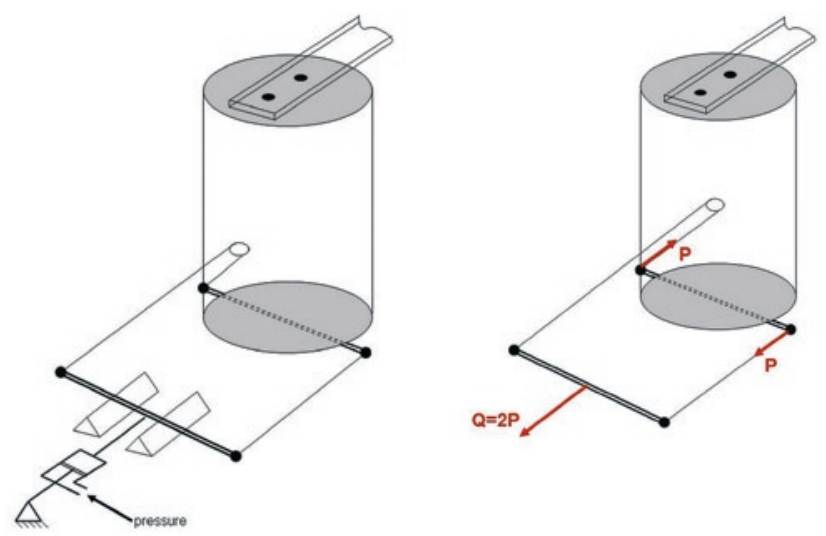

Fig. 6. Schematic sketch of model mounting and the load application system

stability of the structure is acceptable, the elastic nature of the material was assumed in all numerical models. Moreover, because of its low elasticity modulus value (by two orders of magnitude less than this of steel) it was possible to carry out experiments using low values of the applied external loads.

Inner surfaces of the skin have been coated with a reflexive substance which allowed to apply optical polarimetry methods for qualitative determination of stress distribution patterns.

Experiments were carried out with the use of dedicates research set-up (Fig. 5). The model was fixed and loaded according to the schematic drawing shown in Fig. 6. The load was applied by means of the displacement method with the use of a hydraulic servo coupled with a dynamometer.

Two variants of the structure were examined, differing with thickness of the cut-out reinforcing frame $(3 \mathrm{~mm}$ in the first and $6 \mathrm{~mm}$ in the second version). In both cases, skin displacement measurements were taken by means of ATOS optical scanner (Fig. 7). Distribution patterns of optical effects occurring in skins were observed with the use of a reflected light polariscope (Fig. 8). In the course of load application, the relationship between the torque moment value and the structure's total torsion angle was determined which has been assumed to be the quantity representative for the skin state (Fig. 9).

It follows from the obtained results that differences between displacement distribution patterns observed in advances post-buckling states of the examined model versions are small. Making the reinforcing frame twice as thick resulted in little less depths of folds occurring in the area close to the cut-out corner, contributing on the other hand 
a)

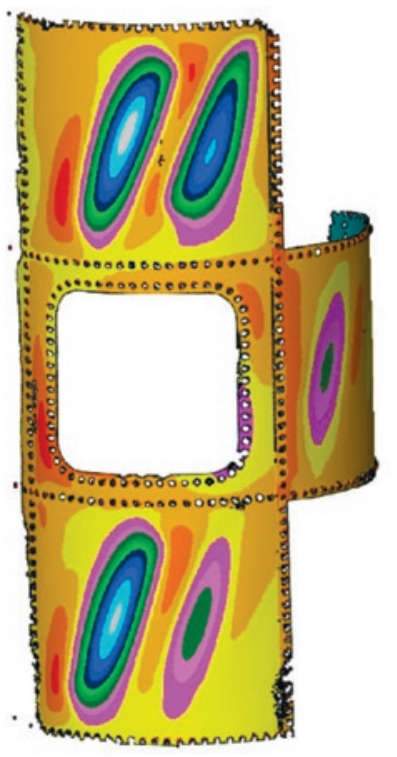

b)

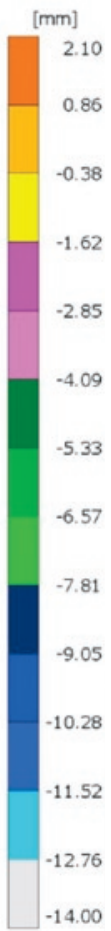

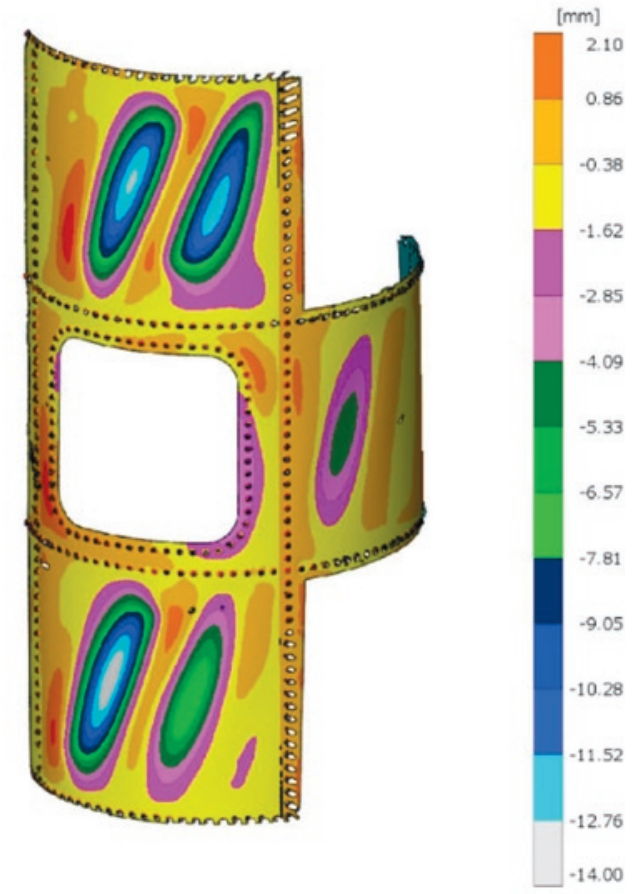

Fig. 7. Skin displacement distribution patterns determined as a result of scanning: (a) model with 3-mm thick frame; (b) model with a 6-mm thick frame
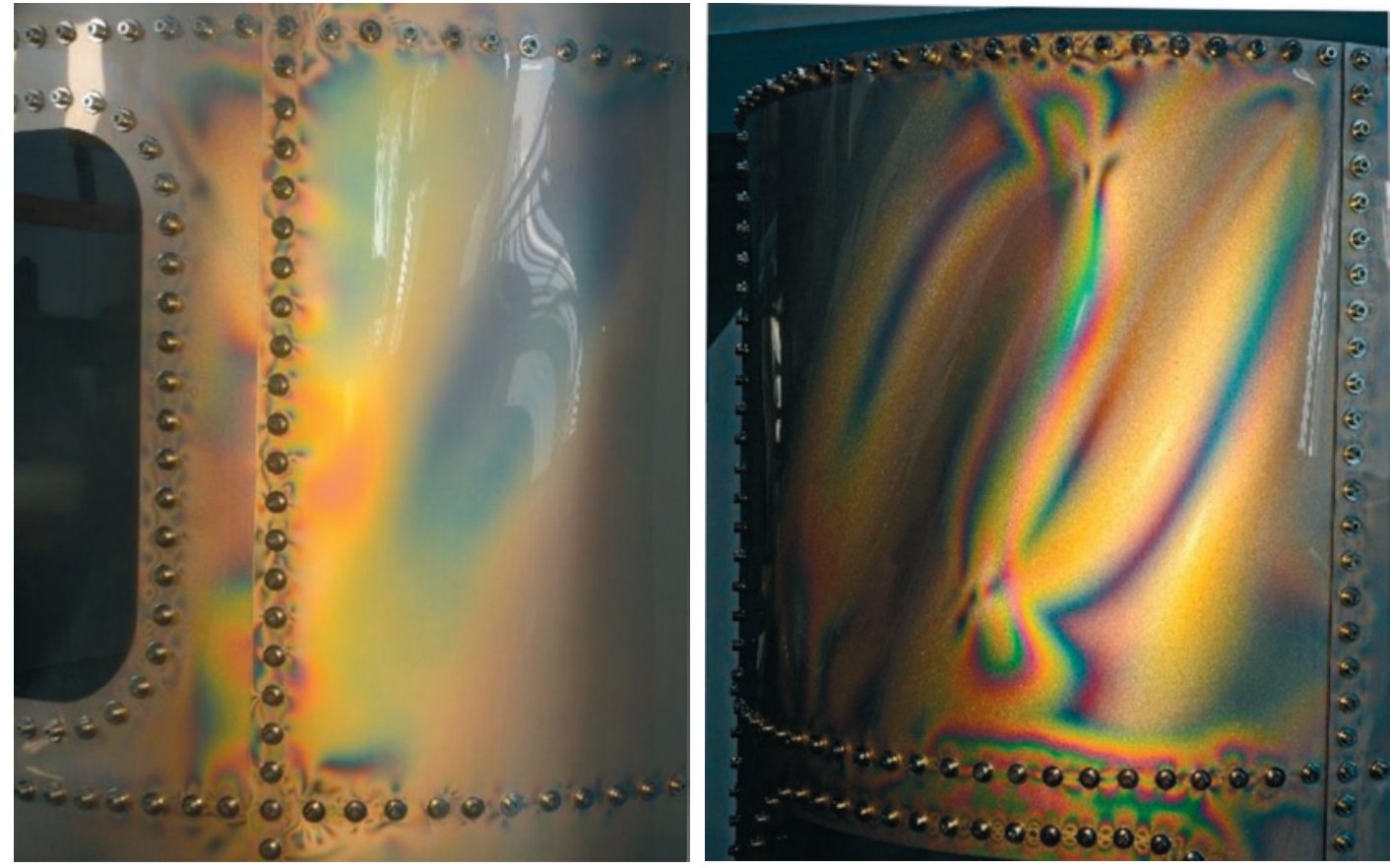

Fig. 8. Distribution patterns of optical effects: (a) in the cut-out area; (b) in the skin segment above the cut-out

to deepening deformations in skin fragments bordering to the cut-out segment (Fig. 7).

Comparison of representative equilibrium paths proves that in the sub-critical range, torsional rigidities of the two structures were virtually identical. Making the frame thicker resulted in the critical load value being increased by about ten percent. Taking into account relatively small increase of the mass structure following from the applied change, the modification may be considered cost-effective from the point of view of the examined object's durability. In fact, an increase of the load value which triggers occurrence of larger deformations re- sults in a decrease of the number of cycles leading to bifurcations and post-buckling deformations which, although admissible, contribute to reduction of the structure's overall service life.

It should be borne in mind that while application of a thicker cutout frame in case of an isolated inspection opening does not affect significantly the overall mass of the structure, introduction of similar modification in case of many cut-outs (e.g. a row of cabin windows) can result in major deterioration of its operating merits. In such cases, it is recommended to undertake more detailed analysis of deficiencies and advantages of the considered design solution change. 


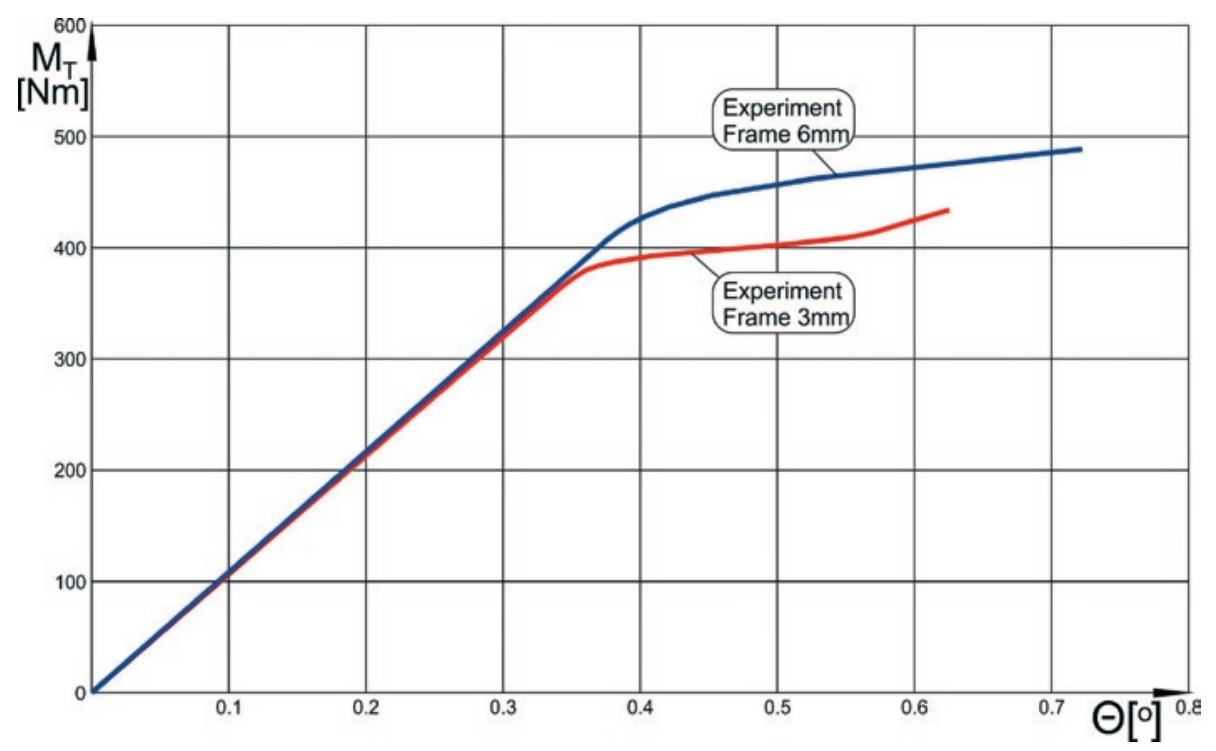

Fig. 9. Representative equilibrium paths - results of the experiment where $\mathbf{u}$ is the state vector containing displacement components of nodes of the structure corresponding to its current geometrical configuration, $\boldsymbol{\Lambda}$ is a matrix composed of control parameters corresponding to the current load level, and $\mathbf{r}$ is the residual vector composed of uncompensated force components related to the current system deformation state. The set of control parameters can be represented by a single parameter $\lambda$ being a function of the load. Equation (1) takes then the form:

$$
\mathbf{r}(\mathbf{u}, \lambda)=\mathbf{0}
$$

called the single-parameter equation of residual forces.

The prediction-correction methods of determining consecutive points of the equilibrium path used in modern software routines contain also a correction phase based on the requirement that the system satisfies an additional equation called the increment control equation or the equation of constraints $[9,17]$ :

$$
\mathrm{c}\left(\Delta \mathbf{u}_{n}, \Delta \lambda_{n}\right)=0,
$$
bordering on the opening whereas the other segments remain in the pre-buckling state. This is the origin of an important design recommendation according to which adding successive skin stiffening elements to the structure skeleton requires taking into account the uneven nature of post-buckling deformations.

The experiment has revealed that post-buckling deformations of the examined skin, in view of their magnitude and rather violent course of the phenomenon, despite their local and elastic nature can significantly reduce the overall service life of the structure. It seems therefore to be necessary to introduce additional stiffening elements to its crucial zones.

The research cycle described here was based on assumption that determination of the effect of design changes on the nature of postbuckling deformations and the critical load value can be a subject of numerical simulations. However, satisfactory conformity of physical properties represented by numerical and laboratory test models remains the fundamental criterion of credibility of the obtained results. The assessment of appropriateness of initial models was therefore based on comparison of deformation patterns and courses of representative equilibrium paths observed in structures subject to test and their numerical models implemented by means of the finite elements method.

\section{Numerical analyses}

Numerical models of the examined structures were implemented with the use of MSC PATRAN/MSC MARC software. In view of the necessity to reflect the phenomena related to the loss of stability in numerical models, nonlinear procedures were used in the analyses which allowed to take into account large deformations and the resulting changes in orientation of active force vectors $[3,5]$.

The fundamental link in an nonlinear problem determining the relationship between the state of a structure and the load in the finite elements method is the so-called equilibrium path of the system, representing in general as a hypersurface in the hyperspace of states [4, 5]. The relationship represents fulfilment of the equation of residual forces in a matrix form $[9,15]$ :

$$
\mathbf{r}(\mathbf{u}, \mathbf{\Lambda})=\mathbf{0},
$$

where the increments:

$$
\Delta \mathbf{u}_{n}=\mathbf{u}_{n+1}-\mathbf{u}_{n}, \text { and } \Delta \lambda_{n}=\lambda_{n+1}-\lambda_{n}
$$

correspond to transition from state $n$ to state $n+1$.

In view of lack of possibility to represent equilibrium paths for systems with more than 2 degrees of freedom in a form of 2D plots, in practice, for the purpose of comparison, the so-called representative equilibrium paths are used that represent a functional relationship between a selected parameter characterising deformation of the system and a single control parameter related to the applied load. Reliability of results obtained from FEM-based nonlinear numerical analyses is usually accepted when a satisfactory convergence is found between two representative equilibrium paths, namely the actual one determined in the course of an experiment and this obtained numerically. It is also necessary to obtain convergence between the forms of deformations following from the calculations [9] with results of the corresponding experiment. On the grounds of the rule of uniqueness of solutions, according to which one and only one distribution of the reduced stress corresponds to each deformation state, the obtained reduced stress distributions in the deformed skin can be therefore also considered reliable [11].

As the nonlinear numerical analysis is an iterative process aimed at finding successive equilibrium states, its correctness is, to a large degree, determined by correct choice of the prognostic method, the correction strategy, and a number of control parameters. In the case described here, the Newton-Raphson method was used in combination with the control parameter correction strategy (the so-called state control). Usually, when carrying out numerical analyses of post-buckling deformations, it is necessary to employ more advances correction strategies from the group of the so-called arc-length control methods which include e.g. the Riks-Ramm strategy [17] and the Crisfield strategy [4]. However, computational practice reveals that with respect to shells with relatively large curvatures, including cylindrical ones, proper selection of the set of parameters controlling nonlinear analysis in combination with basic correction strategies allows to obtain correct solutions with significantly reduced computation time.

Numerical models of the examined structure variants were based on the same overall geometrical layout (Fig. 10). 


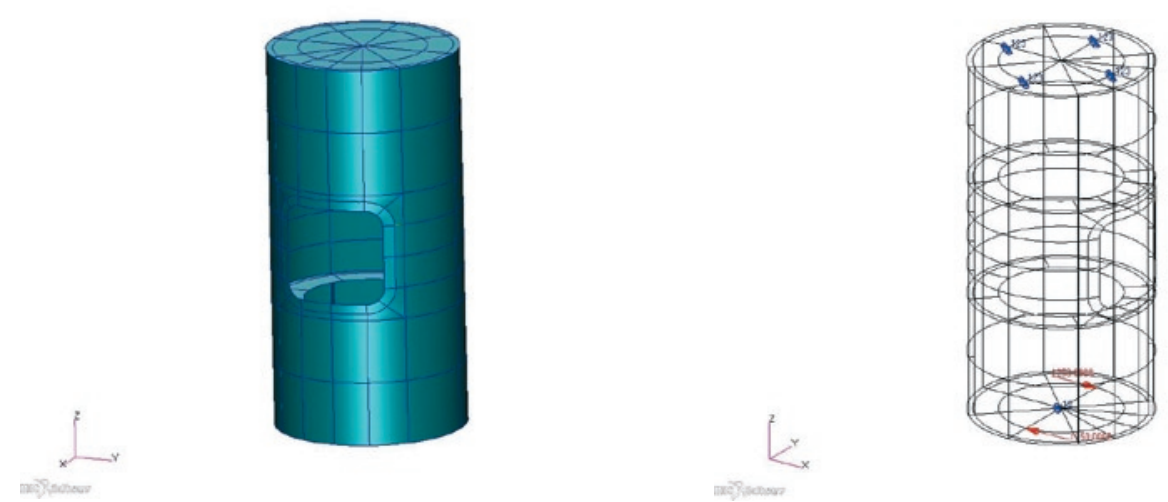

Fig. 10. Geometrical model of the structure with schematic view of its mounting and the load application system

a)

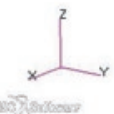

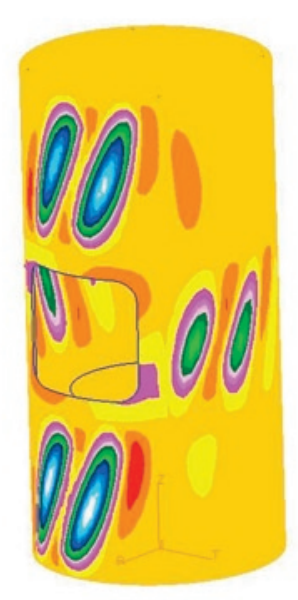

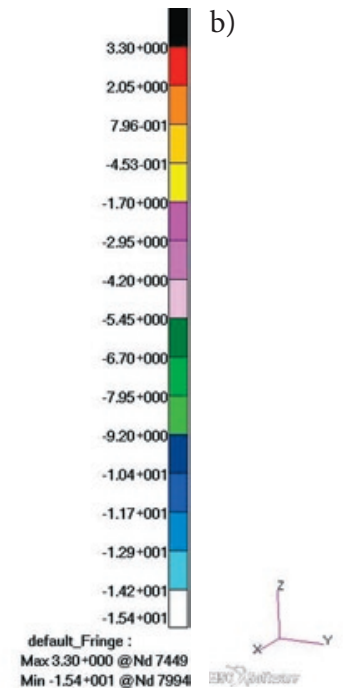

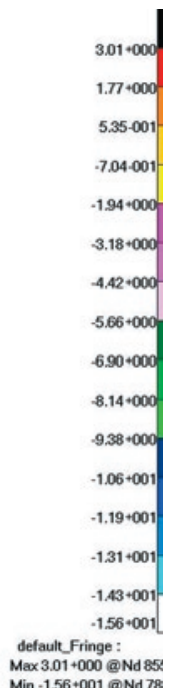

Fig. 11. Resultant displacement distribution patterns (in mm): (a) model with 3-mm thick frame; (b) model with 6-mm thick frame

Numerical models were based on surface-type structures, with the use of thin-shell elements, thick-shell elements (to represent frames and stringers), and four-node shell elements with bilinear shape functions. With the assumed mesh density, about 10,400 nodes and about 10,500 elements were used in total.

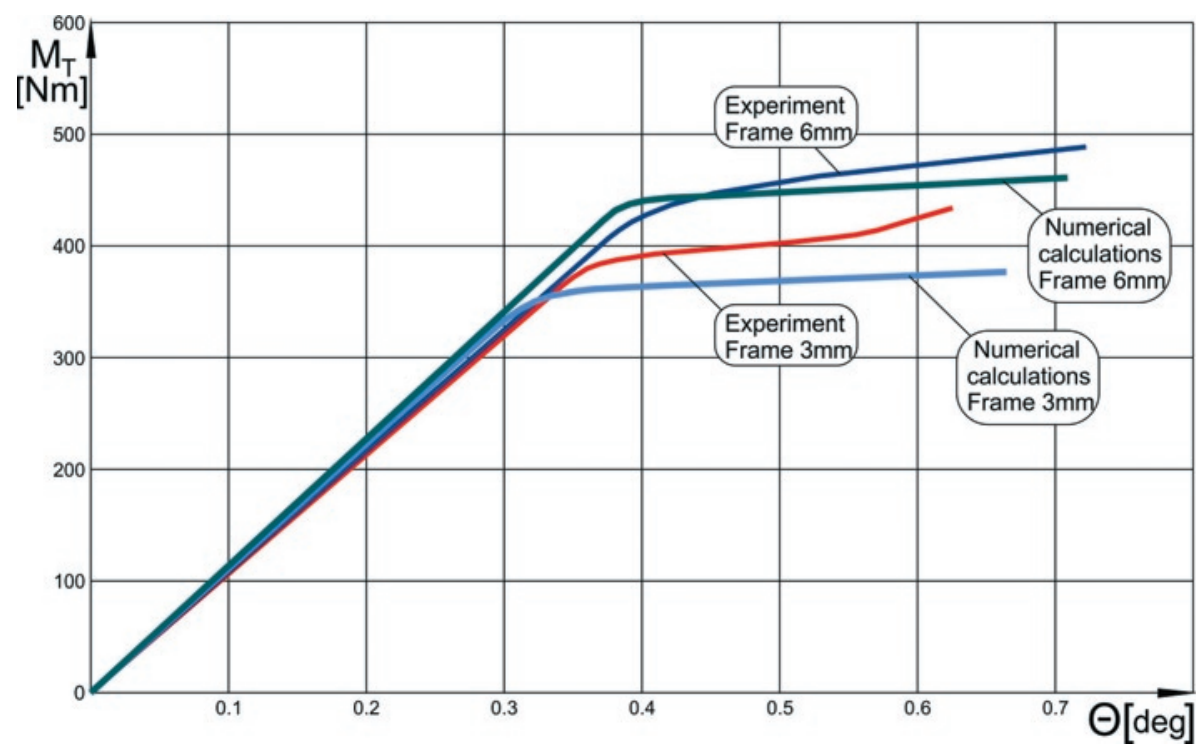

Fig. 12. Comparison of representative equilibrium paths
Resultant displacement distribution patterns obtained for the examined models from nonlinear numerical analysis are presented in Fig. 11.

The obtained deformation distribution patterns conformed to experimental test results both qualitatively and quantitatively. Based on result of numerical analyses, representative equilibrium paths were determined representing relationships between the overall angle of torsion of the structure and the torque moment value. The characteristics obtained from experiments and those calculated on the grounds of numerical analyses are juxtaposed in Fig. 12.

It should be emphasised that the presented characteristics were drawn with the use of data obtained from measurements carried out for steady-state conditions. In the course of origination and further development of post-buckling deformations, a number of local bifurcations arise as a result of which some subsets of state parameters are subject to changes. Such changes may result in occurrence of abrupt offsets in representative characteristics; however, from the point of view of durability and reliability of the structure, its seems to be unnecessary to reproduce them in detail.

Consistence of the two model versions should be acknowledged satisfactory. In the linear regime, the similarity can be considered 
a)

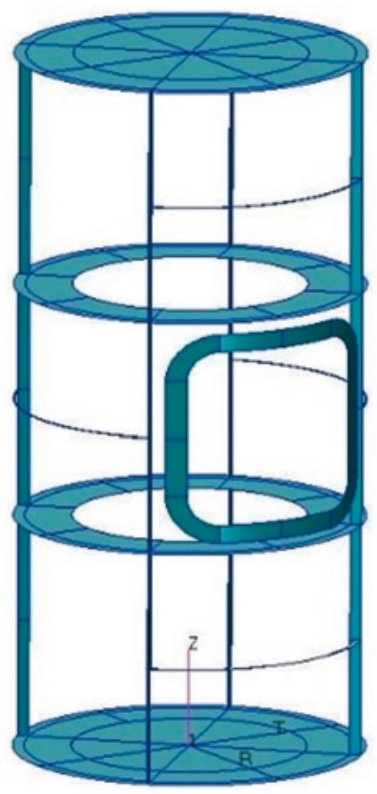

b)

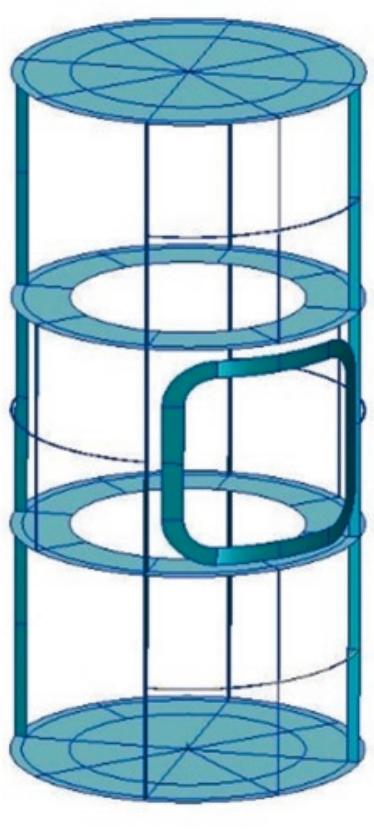

Fig. 13. Modified models of the examined structures: (a) version with fragmentary frames, (b) version with fragmentary frames and stringers

a)
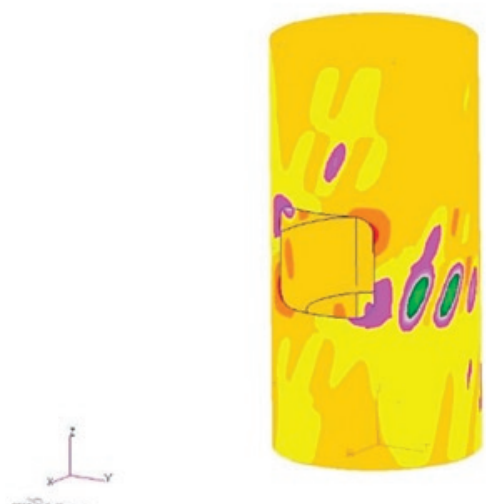

b)

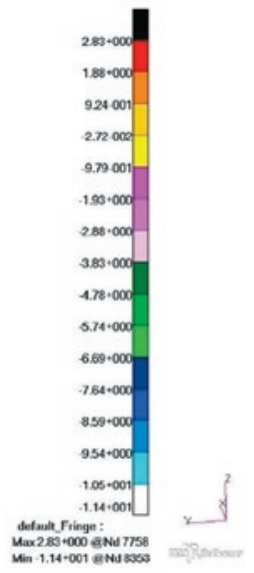

complete, while in the post-buckling range, discrepancies between calculated control parameters and those obtained from the experiment, for determined states of the structure, do not exceed $9 \%$ ( $7 \%$ in case of $6-\mathrm{mm}$ thick frame).

It can be therefore stated that that the adopted numerical models are appropriate and show properties satisfactorily consistent with those of actual objects.

As it has been already mentioned above, deformation patterns and magnitude of the displacements connected with them seem to be unfavourable from the point of view of the structure reliability. It seems therefore to be justified to undertake an attempt to introduce additional skeleton elements the purpose of which would be to stiffen crucial areas of the skin at the structure mass increase kept as small as possible.

The verified numerical models were used to determine properties of the modified structure variants. Successive modifications were limited to providing the structure's skeleton with additional components aimed at local improvement of rigidity and inducing a change in post-buckling deformation

Fig. 14. (a) Displacement distribution (in $\mathrm{mm}$ ) in the model with fragmentary frames; (b) a fragment of the rear portion of the structure

a)
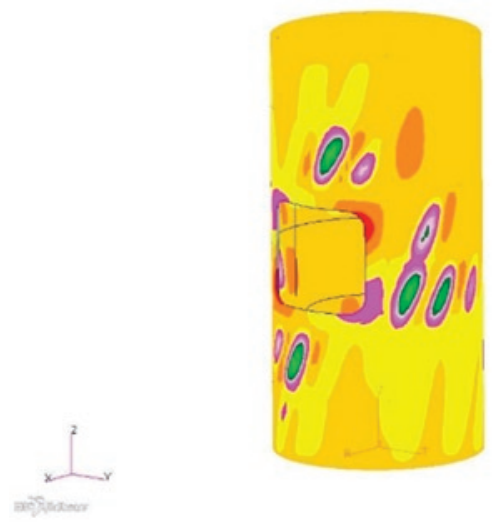

b)

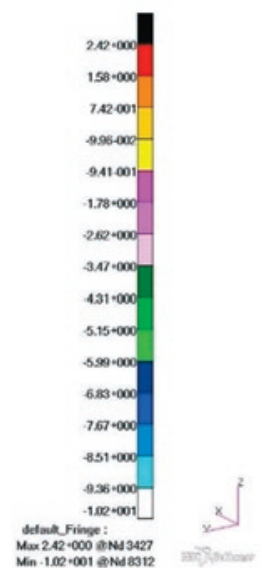

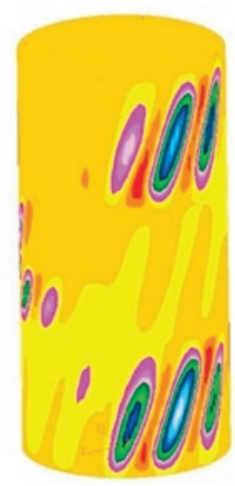

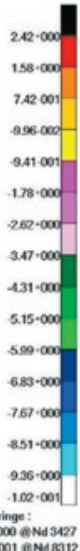

Fig. 15. (a) Displacement distribution (in $\mathrm{mm}$ ) in the model with fragmentary frames and stringers; (b) a fragment of the rear portion of the structure 
patterns. The process was aimed at determining a solution as favourable as possible from the point of view of durability and reliability of the structure, with the increase of its mass limited to a minimum at the same time.

The first of the alternative solutions consisted in providing the skin segments bordering to the cut-out with additional skeleton components in the form of fragmentary frames. In another version of the structure, fragmentary stringers have been also added (Fig. 13).

Numerical calculations were carried out in both cases by means of the set of procedures the same as this used in earlier models. The sizes of new tasks did not change significantly.

Post-buckling displacement distribution patterns obtained from the analyses were characterised with forms significantly differing from those observed in case of initial structures (Figs. 14 and 15).

In both cases, presence of additional skeleton components resulted in significantly increased rigidity of skin segments bordering to the cut-out, forcing at the same time occurrence of post-buckling deformations in the structure's

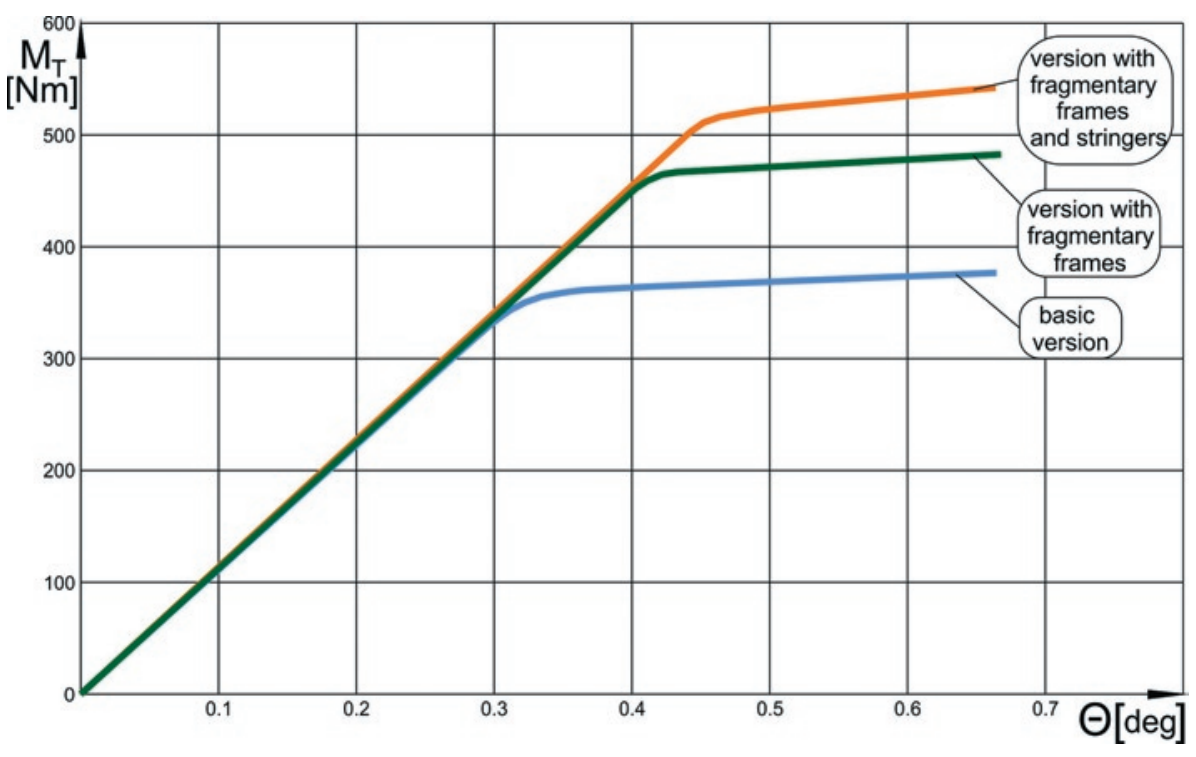

Fig. 16. Comparison of representative equilibrium paths for numerical models with a 3-mm thick frame reinforcing the cut-out rear segments (opposite with respect to the opening). It can be therefore claimed that the adjustment to the design solution resulted in more even reaction of the structure and reduction of maximum postbuckling displacement values. As far as the quantitative comparison is concerned, the solution employing fragmentary stringers seems to be more favourable, as in this case the maximum displacements are smaller by about $10 \%$ compared to the structure in which only fragmentary frames were used as stiffening components. It should be however emphasised that the presented results correspond to maximum load values applied in the course of the experiment. In operating conditions, deformations of this magnitude are in general inadmissible which follows from the necessity to maintain stiffness of the whole structure.

When developing a numerical model to be verified experimentally it is appropriate to compare magnitude and nature of deformations within a wide range of load values as this allows to assess appropriately the properties of the virtual structure and their conformity with properties of its actual counterpart. It is assumed that in real-life operating conditions, there are post-buckling deformations corresponding to relatively small increases of representative structure state parameters with respect to their values occurring at critical loads.

Under such assumption, a ten-percent difference between maximum displacement values observed in the above-presented structures does not seem to be significant. An important factor allowing to assess reliably the properties of the proposed solutions is the juxtaposition of representative equilibrium paths and comparing them with the characteristic corresponding to the initial version (Fig. 16).

It follows from the presented characteristics that the proposed modifications result in an increase of the critical load in the range of about $20-30 \%$ which, at expected small increase of the mass, seems to be a satisfactory figure. Although introduction of fragmentary stringers results in increased stiffness of the structure and higher critical load value, it seems to be advisable to precede selection of the target solution with detailed analysis of mass increase for the complete structure including the proposed modifications. For the model material used in the course of experimental tests, the estimated mass increase with respect to the initial structure mass was about $0.5 \%$ for the solution employing fragmentary frames and about $1 \%$ for the version with fragmentary frames and stringers. If therefore the considered structure corresponds to a fragment of aircraft fuselage with a single inspection

opening, application of fragmentary stringers must be acknowledged as a viable solution.

\section{Summary and conclusions}

On the grounds of experimental test it has been proven that by increasing rigidity of a frame reinforcing the cut-out edge, only relatively small increase of rigidity of the analysed structure is obtained. Usefulness of application of modifications of that type depends of location and quantity of cut-outs in actual aircraft structure. In case when the analysed cut-off is a repeatable fuselage feature, e.g. a passenger cabin window edge, the effect of increased mass of the reinforcing frame an the structure as a whole on its operating durability and reliability should be a subject of separate detailed analyses.

The purpose of the presented considerations was also to point out a potential for prospecting for alternative design solutions allowing to increase the service life of the structure. The proposed methodology consist in using results of a dedicated experiment for developing an appropriate initial numerical model implemented within the framework of the finite elements method and elaborating it be means of gradual modifications.

In the light of the above-presented results, the methodology seems to be effective. It allows to eliminate, in a relatively easy way, the design errors reducing potentially the service life of the structure by means of a number of numerical tests, reducing thus to a minimum the number of necessary experiment and minimising the related costs.

Experimental tests carried out on initial design solutions allow to elaborate appropriate numerical models characterised with high consistence of their rigidity-related properties with those of actual structures which allows to assume that results obtained from nonlinear numerical analyses of models in which modifications were introduced are reliable.

It should be however emphasised that the search for new and more effective versions of a structure by introducing successive modifications to numerical models means continuously increasing departure from the verified initial solution and thus decreasing reliability of the obtained results. It seems therefore to be necessary to verify experimentally the structure in its target form recognised as the satisfactory one from the point of view of the adopted criteria.

The presented solutions alternative with respect to the initial design are only some examples of modifications aimed at increasing 
operating stability of the structure. It seems to be appropriate to carry out a number of another numerical tests allowing to identify flaws and merits of a sequence of design solutions. For instance, it would be advisable to determine the effect of presence of additional fragmentary skeleton components in rear skin segments which, in case of stiffening applied to areas bordering to an opening, are subject to large post-buckling deformations.

It is planned that the solutions assessed as the most promising will be tested experimentally and final versions of the numerical models possible elaborated.

\section{References}

1. Arborcz J. Post-buckling behavior of structures. Numerical techniques for more complicated structures. Lecture Notes In Physics 1985; 288: 83-142.

2. Aborcz J., Hol J.M.A. Recent development in shell stability analysis, Report LR-633 Faculty of Aerospace Engineering. Delft: University of Technology, 1990.

3. Bathe K. J. Finite element procedures. Prentice Hall, 1996.

4. Crisfield M. A Non-linear finite element analysis of solid and structures. J. Wiley \& Sons, 1997.

5. Doyle J.F. Nonlinear analysis of thin-walled structures. Springer-Verlag, 2001, http://dx.doi.org/10.1007/978-1-4757-3546-8.

6. Dębski H., Kubiak T., Teter A. Numerical and experimental studies of compressed composite columns with complex open cross-sections. Composite Structures, 2014; 118: 28-36, http://dx.doi.org/10.1016/j.compstruct.2014.07.033.

7. Dębski H., Kubiak T., Teter A. Experimental investigation of channel-section composite profiles' behavior with various sequences of plies subjected to static compression. Thin-Walled Structures, 2013; 71: 147-154, http://dx.doi.org/10.1016/j.tws.2013.07.008.

8. Dębski H. Experimental investigation of post-buckling behavior of composite column with top-hat cross-section. Eksploatacja i Niezawodnosc - Maintenance and Reliability, 2013; 16 (2): 1056-109.

9. Felippa C. A., Crivelli L. A., Haugen B. A survey of the core-congruential formulation for nonlinear finite element. Archive of Computer Methods in Engineering, 1994, http://dx.doi.org/10.1007/BF02736179.

10. Kolakowski Z., Mania R. Semi-analytical method versus the FEM for analysis of the local post-buckling of thin-walled composite structures Composite Structures, 2012; 97: 99-106, http://dx.doi.org/10.1016/j.compstruct.2012.10.035.

11. Kopecki T., Mazurek P. Problems of numerical bifurcation reproducing in post-critical deformation states of aircraft structures. Journal of Theoretical and Applied Mechanics, 2013; 51(4): 969-977.

12. Kopecki T., Mazurek P. Numerical representation of post-critical deformations in the processes of determining stress distributions in closed multi-segment thin-walled aircraft load-bearing structures. Eksploatacja i Niezawodnosc - Maintenance and Reliability, 2014; 16(1):164-169.

13. Li C., Wu Z. Buckling of $120^{\circ}$ stiffened composite cylindrical shell under axial compression - Experiment and simulation. Composite Structures, 2015; 128: 199-206, http://dx.doi.org/10.1016/j.compstruct.2015.03.056.

14. Lynch C. A. Finite element study of the post buckling behavior of a typical aircraft fuselage panel. PhD Thesis, Queen's University Belfast, 2000.

15. Rakowski G., Kacprzyk Z. The finite elements method in mechanics of structures. Oficyna Wydawnicza Politechniki Warszawskiej, 1993.

16. Rudawska A., Dębski H. Experimental and numerical analysis of adhesively bonded aluminium alloy sheets joints, Eksploatacja i Niezawodnosc - Maintenance and Reliability, 2011; 49(1): 4-10.

17. Riks E. An incremental approach to the solution of snapping and buckling problems. International Journal of Solid and Structures, 1979; 15: 529-551, http://dx.doi.org/10.1016/0020-7683(79)90081-7.

18. Sonat C., Topkaya C., Rotter J.M. Buckling of cylindrical metal shells on discretely supported ring beams. Thin-walled Structures, 2015; 93: 22-35, http://dx.doi.org/10.1016/j.tws.2015.03.003.

19. Teter A., Kołakowski Z. Coupled dynamic buckling of thin-walled composite columns with open cross-sections. Composite Structures, 2013; 95(1): 28-34, http://dx.doi.org/10.1016/j.compstruct.2012.08.006.

20. Yeh M., Lin M., Wu W. Bending buckling of an elastoplastic cylindrical shell with a cutout Engineering Structures, 1999; 21(11): 996-1005.

\section{Tomasz KOPECKI \\ Przemysław MAZUREK \\ Tomasz LIS}

Department of Mechanical Engineering and Aviation

Rzeszów University of Technology

al. Powstańców Warszawy 12, 35-959 Rzeszów, Poland

\section{Dorota CHODOROWSKA}

State Higher Vocational School in Krosno

ul. Wyspiańskiego 20, 38-400 Krosno, Poland

E-mail: tkopecki@prz.edu.pl, pmazurek@prz.edu.pl dorota.chodorowska@pwsz.krosno.pl 